\title{
MAPPING ARTISTIC RESEARCH IN FILM
}

\author{
(ED) \\ MANUEL JOSÉ DAMÁSIO \\ JYOTI MISTRY
}

Special issue: Mapping Artistic Research

Jyoti Mistry is Professor in Film at HDK-Valand Academy, University of Gothenburg in Sweden. She works with film both as a research form and as a mode of artistic practice. Her critically acclaimed films have screened at numerous festivals and her installation work draws from cinematic traditions but is often re-contextualized for galleries and museums. She has been invited to numerous international teaching programs in Africa, Europe and the USA. Mistry has published extensively in areas of film practice, pedagogy and research as it relates to archive, memory, race and gender politics. In 2016 she was recipient of the CILECT (Association of International Film Schools) Teaching Award in recognition for innovation in practices in film research and pedagogy. Currently, she is the principal research investigator on a BRICS (Brazil, Russia, India, China, South Africa) cross cultural project that explores image-making practices.

https://www.gu.se/en/about/find-staff/jyotimistry

Manuel José Damásio is Professor at Lusófona University and the Head of the Film and Media Arts Department (DCAM) and a member of the management board of CICANT. He holds vast experience in Higher Education management, consulting and production management in different areas of audiovisual. He is currently the chair of GEECT - European Grouping of Film and Television Schools and Board Member of CILECT - The International Association of Film and Television Schools and a member of the European Film Academy.

He is a member of the National Education Council in Portugal (CNE). He is a member of the former board of the TV studies section of ECREA The European Association of Communication Research. He is a member of the National Panel of projects evaluation for ICA - The Portuguese Film Institute and regularly works as a panel member in education and research quality assurance and evaluation processes at national and international level (E+, COST, EQ-ARTS, HETAC, and others). He has been the PI of more than 15 major national and international innovations, training and R\&D projects funded by different bodies (E+, H2020, FCT, FP6, FP7, ISF, P2020, ESF, Creative Europe, MEDIA). 
Artistic research has been on the top of the agenda of the current GEECT board since it was elected in the Mumbai 2018 Congress. Research represents a tremendous challenge for most of our schools. The first of these challenges derives from the current status of film education in Europe, where film schools are traditionally tied to educational models of the conservatoires which are, for the most part, still distinct from the wider academia. This longstanding focus on the elements of craft and art making, results in an orientation that was, and still continues to be, practical, placing the master/disciple relationship at the heart of the educational process. In the last decades, these institutions have been under a great deal of pressure. The reforms of the Bologna process had far-reaching ramifications for these institutions by replacing some training regimes of flexible length with ones that could accommodate the ordered cycle of degrees proposed by the reform. Further faced with the need for European Standards compliance, namely those articulated in the "Dublin descriptors" of 2004, and more recently in the European Qualifications Framework (EQF), many of these institutions started transforming themselves by engaging in a process of "academicisation". This resulted in great tension between the original nature and focus of these institutions on professional-level training and the much wider mission to which academic institutions are nowadays ascribed. The result was that many film schools went through a period of turmoil that has greatly hindered their ability to experiment with structural changes the likes research activities of high level imply. Throughout this period, these institutions, and many other programs that have emerged inside universities based on similar educational models, have continued to pursue progressive pedagogical approaches supported by their special heritage, their pragmatic response to individual working methods, and their close connections to students and their work. Yet, many impediments to these HEI activities remain, like legal or institutional constraints that disallow the introduction of the subject as a self-sufficient element of a doctoral degree, or concerns over financial viability due to the costly nature of teaching, resulting in pressure for greater massification and a decrease in the intensive use of expensive state-of-the-art technologies. Nowadays, these schools are required to develop research but still many of them do not have both the means and the experience to pursue research activities at the level required, namely by national and international quality assurance and funding bodies. And even in the case of member schools that are part of larger HEI with bigger resources, the fact artistic research is still a relatively young field, contributes to greater difficulties in getting support and funding and a lower level of recognition of its impact and value.

The idea for this special issue came out of the recognition that an association such as GEECT must react to this state of affairs and should contribute to its member schools' ability to offer learning and teaching programmes that are built on state-of-the-art knowledge in the field. We envision this special issue as a show case of the research being conducted in different schools and also as a statement in favour of the relevance of artistic practice based research. The articles here included are all examples of how artistic research is undertaken in film and media arts, and achieves its results both within those disciplines, as well as often in a transdisciplinary setting, combining artistic methods with methods from other research traditions

In a context where film schools have been increasingly driven to conduct artistic research, we believe the development of the research environment is essential. This objective is just as important as the research outputs and their impact, and this has become a high strategic priority for GEECT that we also try to materialize via this special issue.

This special issue is a direct consequence of the conference GEECT held in January 2020 GEECT on Artistic Research and Film Practice, which was hosted at Stockholm University of the Arts, in the Film and Media Department. The conference 
created an environment for robust debates and discussion that challenged the definitions of what constitutes artistic research in film. The papers assembled here capture the breath and scope of how artistic research is conducted, experienced and accounted for in film schools and film programmes in the practice with, in and through film, and constitutes a small contribution to the on-going debates about the relevance and impact of artistic research.

This special edition on Mapping Artistic Research, is an important opportunity to show how technology has evolved our understanding for example of, space and story, through VR and practitioner perspectives that have resulted in changed work flows and its relationship to the industry and the individual artist.

In Axes of tension: navigating craft, institution and industry as an art-researcher in film and new media, Nadja Lipsyc, Camilla Jaller and Frederick Howard, explore these relations and discuss how AR researchers in film and new media can have radically different practices depending on their expectations towards the project and their abilities. In this paper not only discuss the challenges at-researchers face but also how the institutional, industrial and artistic context they operate in influences and utterly determines the result of their work.

A completely different approach on the affordances of technology for artistic creation and production is taken by Christian Iseli, Stefan Dux and Miriam Laura Loertscher, that in their paper titled The Aesthetics and Perception of Documentary Film: A mixed methods approach and Its implications for Artistic Research discuss how innovations in camera technology have affected the visual aesthetics of documentary films since the 1990s. The paper focuses on the uses of interdisciplinary research geared towards a practice based approach and freely articulates different types of methods, from more quantitative and experimental ones to more qualitative approaches, in order to critically evaluate the relation between research methods and the exploitation by the researchers of the aesthetic potential of filmic products used as research instruments. The paper thus focuses on one of the core challenges artistic research manifested in the famous trichotomy about the balance between art and research and how the two must intertwine one with the other: "Research about / for / through Art | Art about / for / through Research" (Dombois, 2009).

Artistic research has revitalised teaching strategies by broadening and strengthening the scope of topics and approaches that inform research questions that have shaped critical pedagogies as an approach. This is made vivid in the papers on teaching which include informative case studies and reflections. The examples of teaching show how it is no longer possible or desirable to assume a singular approach or Eurocentric approach even in Europe but rather to create scope to draw from multiple perspectives, numerous film histories and aesthetics to widen the exemplar films in the curriculum. A good example of this is Elen Lotman paper entitled Pedagogical Experiment with Portrait Lighting in combination with different actor's intent in the case of novice Actors that explores the interaction between portrait lighting and acting in the context of pedagogical practices. The paper describes a number of research activities conducted with and by participating students taking the form of an action research endeavour that tries to implement bridges between pedagogy, acting and cinematography via interdisciplinary activities whereby knowledge is mae explicit. The paper highlights the potential of artistic research and education as a transformational process and alert us to the central role human interactions have in any learning and teaching process.

In Video Essays: Curating and Transforming Film Education through Artistic Research, Estrella Sendra reconfigures the historical institutional separation between film studies and film practice. With the introduction of video essays in film studies as a form of critical "writing" in the film medium itself, the 
paper attends to artistic research as a pedagogic approach in creating a space for teaching-learning as a curated undertaking between teachers and students (not as a hierarchical, binary relation) but co-creators in the classroom (drawing from Paolo Freire's idea of "class members"). Sendra draws from her personal experiences to show the transformative nature of introducing video essays as a tool for learning and assessment which in turn invites a dynamic environment for sharing ideas in the classroom and stimulates creativity.

Some papers explore how identities can be re-imaged by shifting the power relations between practitioners and their subjects which can be explored through artistic interventions that take representational politics in film into account. In Towards a Participatory Approach: Reversing the Gaze when (re) presenting Refugees in nonfiction film, Ram Beiruty traces the processes for collaborative filmmaking from an insider perspective of the Syrian refugee community in Germany. The paper offers an in depth account of how Beiruty worked with a central character, Nudar to create a film that provides more nuanced experience of refugees that goes beyond stereotypes of the Other. By drawing from the theoretical proposition that identity is positioned relationally and always in context (as described by Stuart Hall), the process outlined serves to revise the ethical issues and the power dynamics between the filmmaker's gaze and the subject. Furthermore, by allowing the subject access to the camera and the editing process Beiruty concludes how the experience of this project reveals a set of negotiated contradictions that are not only drawn from the nuclear relationship between the filmmaker and subject but from a number of allied factors like funding, technology and access that impact the expansive, inclusionary promise of participatory filmmaking.

A large multi-tiered research project aimed at shifting the representational framework of stories is captured in Confronting Realities - First Steps, Working on Cinematic Autosociobiographies - it contextualises historical developments with social class concerns and resulted in several film projects through its four-part scaffold approach. Barbara Wolfram, Christina Wintersteiger, Elena Meilicke, Nina Kusturica, Claudia Walkensteiner-Preschl each worked on the research framework in complementary ways to structure a method that included positioning subjectivity as one of the tenants of the research scope. This in turn informed the narrative approaches for the films which the authors detail in their reflections on the process of working through cross disciplinary theoretical propositions. The conclusions detailed relate to advancing artistic research as a strategy in the curriculum that facilitates greater inclusion of student's perspectives from across generations, their linguistics differences and encourages multiple film forms.

The ethics of how to represent the Other is one of the dominant areas of enquiry in artistic research because it is most directly connected to experiments in aesthetic forms. Dominant cinematic conventions reinforce historical and political power structures and by working directly with the language of film itself, these conventions can be subverted. The aim of research using film language and cinematic forms, is not to represent the experiences of marginal peoples but rather to find forms that capture more sharply the utterances of the Other. In other words, rather than speaking on behalf of the Other, experiments with the film form strives to create a visual expression of those layered, negotiated experiences of oppressed peoples, identities that have been formed in relation to power and the narratives that illustrate the construction of those identities. Such an experiment is vividly mapped out in Ram Krishna Ranjan's paper that uses Satyajit Ray's seminal film Distant Thunder (1973) to expose how the Bengal famine of 1943 has never captured the lived experiences of the Dalits; the caste most oppressed by this orchestrated national disaster. Ranjan's multi-layered strategy of re-working and working the images as Contracts of making, viewing and listening: Researching in and through films becomes a strategy of not only subverting the historical and political representation 
of the famine in its cinematic form but is research that interrogates what a Dalit aesthetic might be in cinematic form. In its summation, the paper invites consideration for how film produces knowledge through the artistic form itself and while the written component documents the conceptual process, the interrogation of the ideas is expressed in the aesthetics of his film experiment itself.

Similarly, Nduka Mntambo is engaged with the aesthetic enquiry of cinematic forms and explores the navigational aspects of urban life, particularly in African cities - through his iterative installation project Asymmetries that uses Cinematic Cartographies to challenge the experience of cinema in its mono-focality. Demanding that the spectator be responsible for the viewing and the meaning-making experience; an injunction to action (the emancipated spectator as described by Jacques Ranciere), Mntambo's exegesis gestures to the political necessity of upturning any singular narrative (read colonial history). The layering of stories and the movement required to navigate the installation demands an engagement from the spectator/cartographer as a character in the story that they construct or experience rather than one given to them. The research puts at its centre, the questioning of historical definitions of the collective viewing experience of cinema as a passive encounter. Instead what Mntambo exposes is an inherent contradiction in the collective experience of cinema installation which demands that a spectator be individually responsible as a character for a story they construct.

Our intention with this is inaugural edition is to inspire greater academic and artistic scholarship on artistic research in film and to create a forum to exchange ideas, share experiences and like all research, it aims to broaden our understanding and expand our artistic practices and pedagogy in film.

\section{References:}

Dombois, F, (2009) "0-1-1-2-3-5-8-. Zur Forschung an der Hochschule der Künste Bern“, in:

Hochschule der Künste Bern (Hg.): Forschung. Jahrbuch Nr. 4/2009. Bern 2009, pp. 11-22 